\title{
WestVirginiaUniversity
}

THE RESEARCH REPOSITORY @ WVU

Graduate Theses, Dissertations, and Problem Reports

2018

\section{Understanding Multi-Social Media Platform Use In An Earthquake}

Tonmona Tonny Roy

Follow this and additional works at: https://researchrepository.wvu.edu/etd

\section{Recommended Citation}

Roy, Tonmona Tonny, "Understanding Multi-Social Media Platform Use In An Earthquake" (2018). Graduate Theses, Dissertations, and Problem Reports. 7244.

https://researchrepository.wvu.edu/etd/7244

This Thesis is protected by copyright and/or related rights. It has been brought to you by the The Research Repository @ WVU with permission from the rights-holder(s). You are free to use this Thesis in any way that is permitted by the copyright and related rights legislation that applies to your use. For other uses you must obtain permission from the rights-holder(s) directly, unless additional rights are indicated by a Creative Commons license in the record and/ or on the work itself. This Thesis has been accepted for inclusion in WVU Graduate Theses, Dissertations, and Problem Reports collection by an authorized administrator of The Research Repository @ WVU. For more information, please contact researchrepository@mail.wvu.edu. 


\title{
UNDERSTANDING MULTI-SOCIAL MEDIA PLATFORM USE IN AN EARTHQUAKE
}

\author{
Tonmona Tonny Roy
}

Thesis submitted to the

\begin{abstract}
Benjamin M. Statler College of Engineering and Mineral Resources at West Virginia University
\end{abstract}

in partial fulfillment of the requirements for the degree of

\author{
Master of Science in \\ Computer Science
}

Saiph Savage, Ph.D., Chair

Donald Adjeroh. Ph.D.

Elaine Eschen, Ph.D.

Lane department of Computer Science And Electrical Engineering

Morgantown, West Virginia

2018

Keywords: social media, disaster, earthquake, multi-platform, technologies, digital volunteering

Copyright 2018 Tonmona Tonny Roy 


\section{ABSTRACT}

\section{UNDERSTANDING MULTI-SOCIAL MEDIA USE IN AN EARTHQUAKE}

\section{Tonmona Tonny Roy}

Research on digital volunteering for emergency response has studied specific platforms, resulting in findings isolated from a broader ecosystem where multiple platforms are used. On September 19th, 2017, Mexico was affected by a 7.1-magnitude earthquake, killing hundreds of people and destroying many homes. Communication among people became a difficulty and many people had to communicate about required foods and shelter. People turned to their social media sites to bridge the gap of communication.

This thesis examines how people utilized different technological platforms during the aftereffect of the earthquake. Similar to prior work, our study identifies that technology helps to share important information about a disaster. However, our work also uncovers that multiplatform usage facilitates a new type of help focused on being creative and producing new artifacts, such as building novel tools. We find that individuals who participated in such aid considered that their help was creating a new culture of prevention and tended to participate longer term. 


\section{ACKNOWLEDGEMENTS}

Foremost, I would like to express my sincere gratitude to my advisor Dr. Saiph Savage for the continuous support of this research, for her patience, motivation, enthusiasm, and immense knowledge. Her guidance helped me in all the time of research and writing of this thesis. I could not have imagined having a better advisor and mentor.

Besides my advisor, I would like to thank the rest of my thesis committee: Dr. Donald Adjeroh, Dr. Elaine Eschen, for their encouragement, insightful comments, and hard questions.

Furthermore, I wish to acknowledge the Lane Department of Computer Science and Electrical Engineering for giving me the opportunity to pursue my masters degree in such an academically vibrant environment.

Finally, I am grateful to my parents, my family and my close friends. Without their support, and their love, I would not be able to complete this project. 


\section{Contents}

1 Introduction 1

1.1 Background Information: Massive Earthquake in Mexico..................................... 3

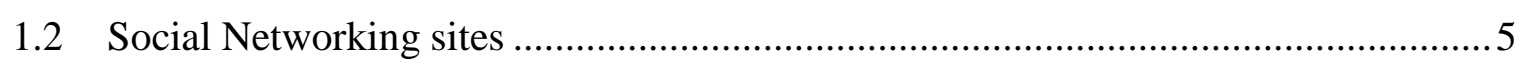

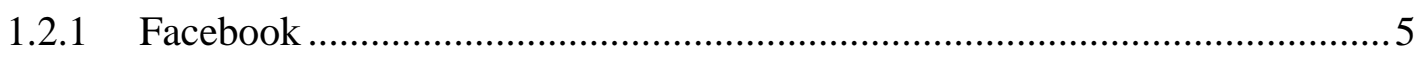

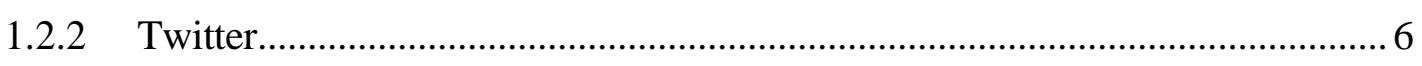

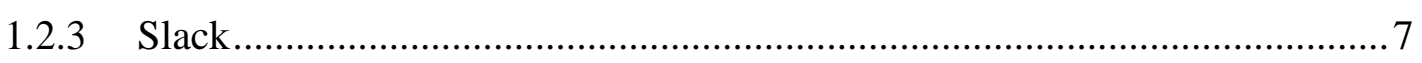

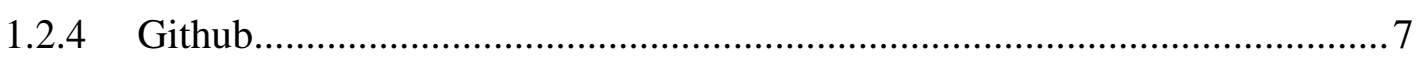

2 Literature Review 9

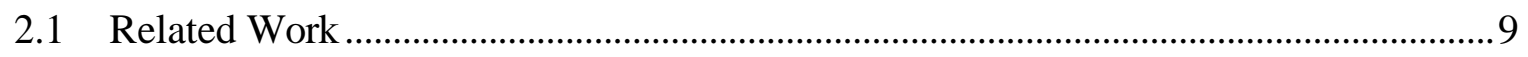

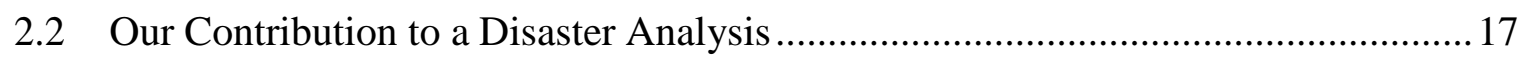

3 Methodology 21

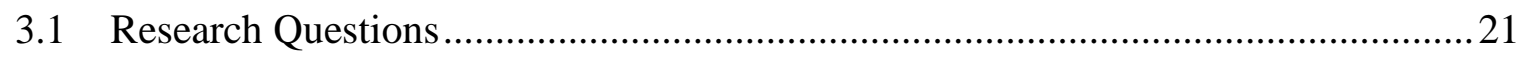

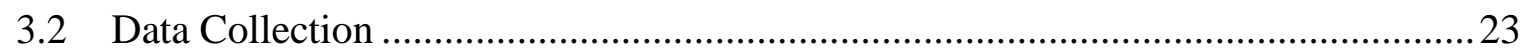

4 R1: Use of different socio-technical platforms 28

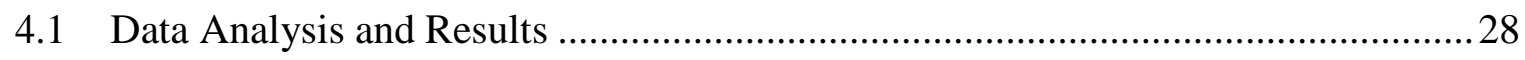

5 R2: Type of help people provide $\quad 35$

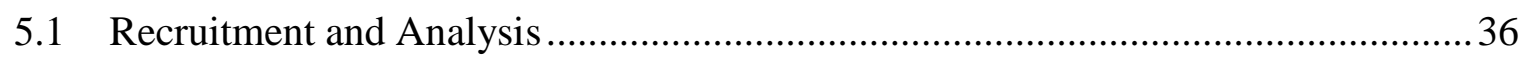

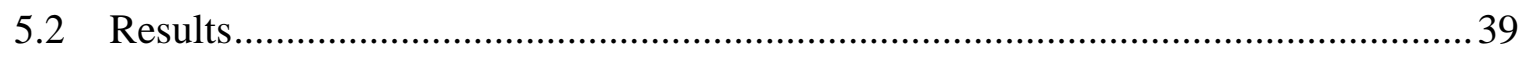


5.3 Bots in Disaster Management

6 Discussion

7 Limitations and Future Work 48 


\section{List of Figures}

2.1 Social Media Functions for Crisis Management [6] ............................................. 10

2.2 Number of Tweets and retweets March1 - March17, 2011 from[15] ............... 15

4.1 Daily number of new posts created across each platform ......................................29

4.2 Daily number of new groups created across each platform. ................................... 31

4.3 The date people started posting about the earthquake vs the number of posts they generated across platforms.

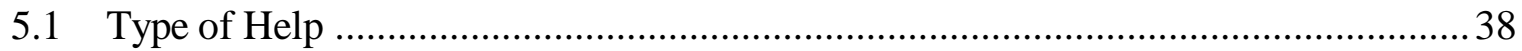

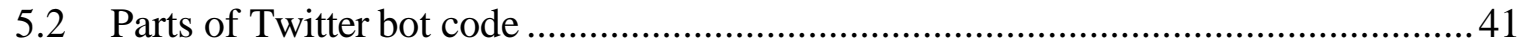

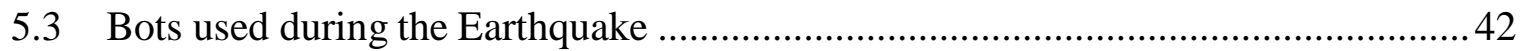




\section{List of Tables}

2.1 Frequency of terms that are relevant to the disaster and measures taken from[15] 16

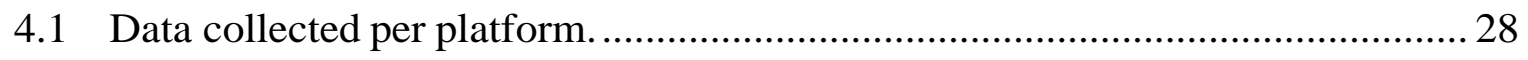

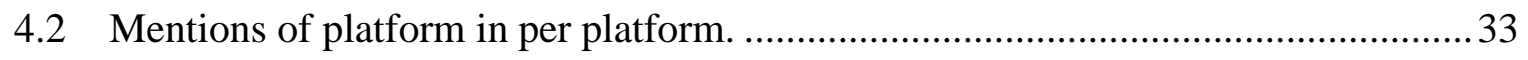




\section{Chapter 1}

\section{Introduction}

Social media is the collective of online communication channels dedicated to community-based input, interaction, content-sharing and collaboration. The term social media denotes a way of communication that is internet-based and enables people to share resources and information [29]. Examples of social media can range from chat servers, forums, websites, Youtube, Facebook, Slack, Github and Twitter. Social media is convenient and useful because it can be accessed through computers, mobile phones, tabs. Even when there is a blockade in cellular tower or a power outage that prevents people from calling or watching TV, social media can be used to communicate with people [14]. During the past decade, a swift change in technologies have led to people interacting and sharing information that was not possible before. Social media therefore, can be a powerful tool in many situations. Social media enables communication activities that were not possible before. For example, Twitter has functionalities to easily and efficiently create networks that can mobilize people all over the world together [13]. If Social media can be systematically used in the case of disasters, it can help many people act swiftly and efficiently. Thus, in recent years several researches have been done on the usage of social media in case of disasters. This thesis focuses on the various technologies used and novel ways of using social tools in the recent massive Mexican 
earthquake that devastated many.

On September 20,2017, Mexico City was hit with a 7.1 magnitude earthquake, killing hundreds of people. The death toll started rising quickly, with people trapped under the debris of the fallen buildings [2]. When there is a catastrophe of this magnitude, it is hard for the government to quickly assist everyone. Many started using social media to spread news about trapped people and supplies needed. Among the social media platforms, Twitter became the main site for exchanging information and mobilizing citizens for action.

In this thesis, we did an analysis of the use of different social media platforms during this time. We did an analysis of how people used the technologies. This paper further analyzes new novel ways of helping by building new tools.

Over the past decade social media and other technologies have been used excessively to provide help in natural disasters. Even in crisis, like uprising, social media applications and the role of the web is discussed [38]. Activists and volunteers all over the world can gather as one through technology. Technology, especially social media, has transformed how people take part in these emergencies. Having rapid access to a wide range of digital information has created new ways of helping during natural phenomena. The four Phase Model of emergency management discussed in one paper [40] shows the how people unite in case of an emergency. Social media has been regularly used during emergencies. One of the large scale uses of technology during the 2013 European flood was discussed in [16]. Technology has become an indispensable tool to organize volunteers to provide assistance.

Widespread social media such as Facebook and Twitter are now frequently used during emergencies. Researchers have been investigating how different social media platforms and technologies facilitate during natural disasters: the offline and online coordination of 
volunteers [16]; or the recruitment and retention of volunteers [31]. Prior work has also advanced in understanding the different interactions that emerge on different social media platforms during natural [33]. Palen and Liu [27] studied how wikis were used to collect information about missing people. Starbird et al. [32] highlighted the role of re-tweeting for filtering and recommending important data related to a natural disaster. White et al. [37] showcased how Facebook pages helped citizens handled activities that were unlikely to be done by official emergency services, such as recovering lost pets.

Nonetheless, a limitation of prior work is that most studies generally investigate specific platforms in isolation, outside the context of the broader online ecosystem [18]. The importance of this limitation was made prominent in recent research highlighting that both Twitter and Facebook facilitated synchronizing aid for flood-affected victims [30].

Our work examines the various technologies used by different types of people in the most recent 2017 Mexican Earthquake. Our contribution in this study is the data collected from different platforms during this time, which is hard to acquire normally. We also did an analysis to understand the social context of the different platforms. This is important in rapid action during a disaster. Throughout the thesis we will go into more detail to describe the social media usage in the Mexican Earthquake of 2017.

\subsection{Background Information: Massive Earthquake in}

\section{Mexico}

The people of Mexico are used to natural disasters. Every year natural phenomena repeatedly impact the country, natural disasters, earthquakes, hurricanes, droughts (among other 
phenomena) are increasingly frequent problems [10]. On September 19, 2017, an earthquake of magnitude [35] 7.1 struck the boundary border between the states of Puebla and Morelos [36] $120 \mathrm{Kms}$ away from Mexico City at 13:14:40 hours. Oddly enough, 32 years before on the same date, a massive earthquake of magnitude 8.1 hit Mexico, taking the lives of about 10,000 people.

During last year's disaster, a considerable number of Mexican citizens turned to use the social tools that were available to help them directly. They were able to inform their needs, dispose of goods such as food and services to help all those affected. Some of them included finding missing person or animals. They used social media in order to gather information about what resources were needed and where. The public knew where to donate and where people needed volunteers. So, people living outside of Mexico were also able to participate and help in some ways for the victim. People on social media knew where victims needed food and clothing and delivered them. The different social tools at hand (BRIDGEFY, FACEBOOK, GOOGLE, TWITTER, WAZE and WHATSAPP) became a quick access way to inform and disseminate information as efficiently as possible [8]

Some other technological tools such as drones, thermal detection cameras, and a robot launched by the Pan-American University also supported civil society in these rescues. [25] With the hashtag \#fuerzaMexico and \#estoEsMexico through Facebook and Twitter users were establishing strategies, notifications of collection centers, specific provision of vehicles, water, food, etc. Platforms such as Facebook and Google made it possible to locate and notify the "I'm okay" status, or to point out that there were people "disappeared" [9]

Human chains were formed in order to clear the rubble and rescue as many trapped people as possible using shovels, buckets, gloves, and the support of Mexican and foreign organizations, 
rescue groups, as well as civilians. [28]

\subsection{Social Networking sites}

A key issue with the current research on social media use in disaster is a lack of specification regarding the type of sites included in the vast area of "social networking" and the assumption that variables such as usage have consistent effects across social media platforms. Moreover, another big hinder are the lack of data collected from these platforms. Such assumptions and restrictions hamper the efforts to make a theory difficult to get an idea of people use social media over the time period of a disaster. Although there have been efforts to analyze social media in disaster [15], the broad analysis of multiple platforms and their usage have yet to be done.

To get a idea of how people are interacting on social media, either actively or passively, it is important to know about the variables that encourage a person to be active and help in social media sites. For example, some users may update their status in order to check in with friends, while other users may update their status in order to self-promote. Reasons for social media use may play an even greater role during disasters. Within this content, this thesis examines the the four most popular Social media sites, developing hypothesis around how the features on each site might be used by the users to facilitate recovery during a disaster crisis handling.

\subsubsection{Facebook}

Facebook is considered the prototypical Social media site. [7]. Facebook has a number of features to users including friend requests, tagging others, posting comments, pictures and 
creating status updates. Most of these features facilitate interaction between a user and their community. The size and connection of one's network is under the control of a user as they can send friend requests, accept or deny a friend request. Moreover, Facebook allows each user to post their own "tatus", a personal statement updating their friends on their activities. These posts help share information during a disaster and help to promote aid.

\subsubsection{Twitter}

Unlike Facebook, few empirical investigations have been done using Twitter. Twitter is a micro blogging Social media platform. It is very different from profile media site like Facebook, because users do not build a full profile on Twitter. Although "conversations" can occur using Twitter, the medium is designed for one way interactions where users "tweet" information to their contacts. Twitter has a maximum word limit of 140 characters. The contacts are labeled as "followers" in Twitter instead of the label of "friends" in Facebook. The process by which users gain followers is different than that of Facebook. Twitter does not require the users to send or accept friend requests nor does it require that users become followers of those following them. Twitter therefor enables people to share their message quickly and on a broader level. According to past researches, Twitter is the most popular platform. Investigating the way people use Twitter during a disaster is very important in order to understand behavioral use of social media.

\subsubsection{Slack}

Slack is a team collaboration tool. Different than Twitter and Facebook, it is not used for 
status updates or sharing information of what people are doing and sharing photos. Slack is a digital work-space that powers a organization or a team. It is a place where one can get things done. So far, Slack has not been analyzed in previous social media researches, to our best knowledge. However, a shocking rise of usage of this site was noticed in the recent Mexican Earthquake. Thus, it can can indicate new way people are using social media during crisis.

Slack works as a work space where an "owner" creates a Slack workspace, recruit's admin to help manage and organize the team, and they together invite and on-board members. A team is a group of people that use Slack to communicate. Your Slack work space is the digital space you and your teammates share to communicate and get work done. Slack work space is comprised of channels. Youll use channels to hold most of your conversations with other members. They can be organized around anything departments, projects, or even office locations and you can create as many as you need. During the Mexican Earthquake of 2017, one organization (CodeMExico) rose and gathered people on Slack in order to organize and structure their interactions and also to create new ways to help victims in the disaster.

\subsubsection{Github}

Github is a website and service that people use to share code. Again, similar to Slack it is not a information sharing platform. It is used to develop projects either alone or together. Again, this was a new platform that was used during the Mexico Earthquake. We saw that people used Github as a tool to build web applications and devices that helped during the crisis. So, studying this platform can be very useful when analyzing people's behavior on the social media. 


\section{Chapter 2}

\section{Literature Review}

\subsection{Related Work}

Here, we broadly discuss existing studies done on technologies and on digital volunteering during a disaster. Studies done on social media platform are hard because of the lack of data. With the increase of privacy conditions and people restricting their feed, it is hard to get a complete picture of social media use. Here we will discuss the existing studies done on platforms and talk about our approach to the analysis and our contribution.

Chan in his paper [6] described the role of social media in crisis preparedness, response and recovery. He explained the four stages where social media can be used across stages of (1) information dissemination, (2) disaster planning and training, (3) collaborative problem solving and decision making, and (4) information gathering. Figure 2.1 illustrates the stages.

This paper describes the functions of social media which is useful in understanding their impact. However, the paper has no case study or analysis of social media use in a disaster. 


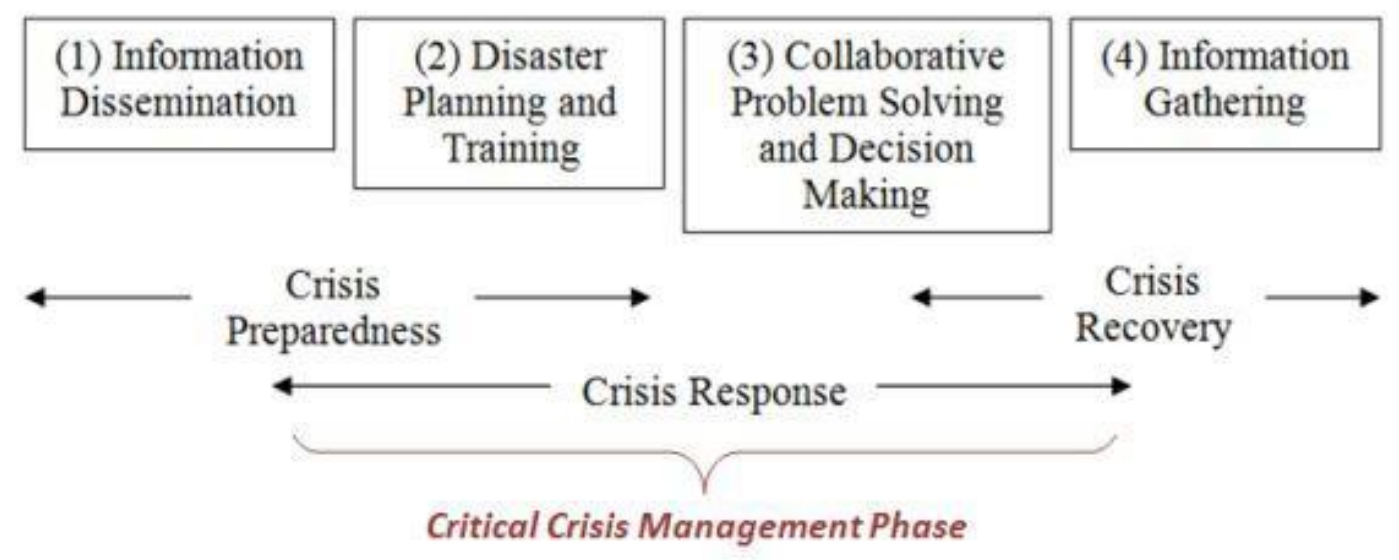

Figure 2.1: Social Media Functions for Crisis Management [6]

In [14], the authors provide information on the public's social media use during disasters.

They examine what prompts the general public to use social media during this time and what deters them. They provide example of social media use during catastrophes like Katrina and Haitian earthquake. Digital volunteerism has become a crucial agent during disaster events all around the world. It was possible by the tools online that help share information and resources, and coordinate action. This emerging aid system develops crowd-sourcing and volunteering among the people affected directly or indirectly affected people. Social media users create new organizations by networking in an attempt to assist in any way they can after a disaster. Emerging organizations that develop during a crisis or disaster use social media tools to give support. They are however more structured and use the social media in a more constructed way. During emergency events, these groups can easily take in and organize more volunteers into their team.

According to [14], in 2011 Virtual Operations Support Teams (VOSTs) were conceived. These teams can manage an enormous quantity of citizen-reported information andimplement immediate action for emergency operations. By monitoring social media and communicating with the victim community, they connect emergency management with virtual volunteers. 
Among the social media volunteers, there are two types. They are Active volunteers and there are Passive volunteers. Social media during disasters create several types of groups: influential social media creators, social media followers, and social media in-actives. Influential Social Media Creators users recognize the gravity of the disaster and are able and motivated to talk about it online. [23] explained that influential social media creators very fast become leaders in creating and sharing information. They found more than $90 \%$ of users tweeting about these disasters were part of a connected group of influencers that emerged quickly after each disaster by analyzing the data. Social Media Followers are those who receive disaster information from influential social media creators either directly or indirectly. Initial research points to the possibility that the majority of those active on social media during disasters may be followers given that the public primarily seems to use social media to share, rather than create, disaster information [14].

The authors collected several case studies and showed the trend of social media use in each disaster [14].

Case Spotlight: September 11, 2001 Terrorist Attacks: The paper started with the case of Terrorist Attacks from September 2009. People back then did not have social media. So, they got their news from Televisions. Along with televisions they used email and telephones. Traffic spiked in the government websites. Moreover, donations were made online through websites.

Case Spotlight: 2005 Hurricane Katrina: Then came the 2005 case study of the Hurricane Katrina. Disaster survivors used location specific media. For the American public, mainstream media sites dominated. Disaster survivors also used the Internet for obtaining information. They again used online for donations and relief. 
Case Spotlight: 2010 Haitian Earthquake: In the 2010 Haitian Earthquake, Twitter was the primary place people turned to. Twitter, however, primarily was not used to obtain news about the disaster. Disaster survivors used social media to tell theirstory.

Case Spotlight: 2011 Tuscaloosa and Joplin Tornados: Social media became very popular during the 2011 Tornados. Social media were the publics first source of disaster information. The public used social media to help find loved ones and offer support. The public also monitored social media for volunteer opportunities.

Case Spotlight: 2012 Hurricane Sandy: The public flocked to the Internet during the 2012 Hurricane Sandy disaster. Twitter was a key venue for sharing information. Facebook as well as Instagram was another key venue for information sharing information. The public turned to Internet-based telephone services to connect.

The author collects case studies from different sources and makes a comparison of improvement and usefulness of social media during disasters over the years. However, the author does not have enough data to perform a detailed analysis of the different social media platforms used.

In the paper [13], the impact of communication during a disaster, response and recovery was examined. Social media can be used passively or systematically. Passively it can be used to disseminate information and connect to people through messages, posts and feed backs.

Whereas, the systematic approach would be to use technology as a medium to conduct emergency communications and issue warning. Moreover, it can be used for receiving user victim's requests for assistance. It can also be used to monitor user activities and post to establish situational awareness. According to the paper, as most popular source to access 
emergency information, Social media site rank as fourth. I individuals and communities have used them to warn others of unsafe areas or situations, inform friends and family that someone is safe, and raise funds for disaster relief. Facebook supports numerous emergency-related organizations, including Information Systems for Crisis Response and Management (ISCRAM), The Humanitarian Free and Open Source Software (FOSS) Project, as well as numerous universities with disaster-related programs. The usage of social media in disasters and emergencies has two categories. One is to use social media to passively spread communication and share through messages, wall posts or polls. This is how most emergency organizations use social media. The second way involves the methodical use of social media as an emergency management tool. This includes warning, requesting help through social media, monitoring user activities to establish situational awareness. Many of these applications remain speculative, while other uses are still in their infancy. Consequently, most emergency management organizations have confined their use of social media to the dissemination of information. However, recent stories and reports have helped improve federal response and recovery capabilities by describing how a wide range of international, state, and local organizations have successfully used social media during emergencies and disasters. It is unclear whether social media have been used to officially issue emergency warnings even though there has been much discussion of using social media to issue emergency warnings that advise citizens to seek shelter, evacuate the area, or take other protective measures [34]. Some social media applications allow users to send notifications to subscribers when a status message is posted or updated. There are some indications that using social media for emergency warnings could be successful.

Digital volunteerism has become a key agent during crisis events all around the globe. It was enabled by online tools that allow their users to share and access useful information, and 
coordinate action. This emerging aid system shows patterns of "convergence" and "spontaneous volunteerism" among the directly or indirectly affected people. After disastrous events occur, social media users create new organizations by networking in an attempt to assist in any way they can.

The role of crowdsourcing through social media has also been discussed in the past [11]. Survivors use social media tools to keep in touch with the world after a disaster. Natural disasters like the tsunami in Japan caused the phone line to be blocked. People therefore, turned to social medias to keep in touch the outside world. Even though social media play a big part, it cannot entirely provide an inherent coordination among people to share information, resources among relief organizations. However, crowdsourcing applications such as twitter are powerful tools in disaster situations.

Disaster relief systems focus primarily on designing coordination protocols and mechanisms to manage government and non-governmental organization (NGO) activities. Research has shown [11]. that it is possible to leverage social media to generate community crisis maps and introduce an inter-agency map to allow organizations to share information as well as collaborate, plan, and execute shared missions. Using crowdsourcing for disaster relief has advantages. Crowdsourced data including user requests and status reports are collected almost immediately after a disaster using social media. Relief organizations can identify and respond to important situations because of the large amount of real time reports.

Crowdsourcing tools can collect data from emails, forms, tweets, and other unstructured methods and then do rudimentary analysis and summaries, such as by creating tag clouds, trends, and other filters.

The paper describes the importance of crowdsourcing and media use in a disaster. There is however, no example of such use in a specific disaster. 


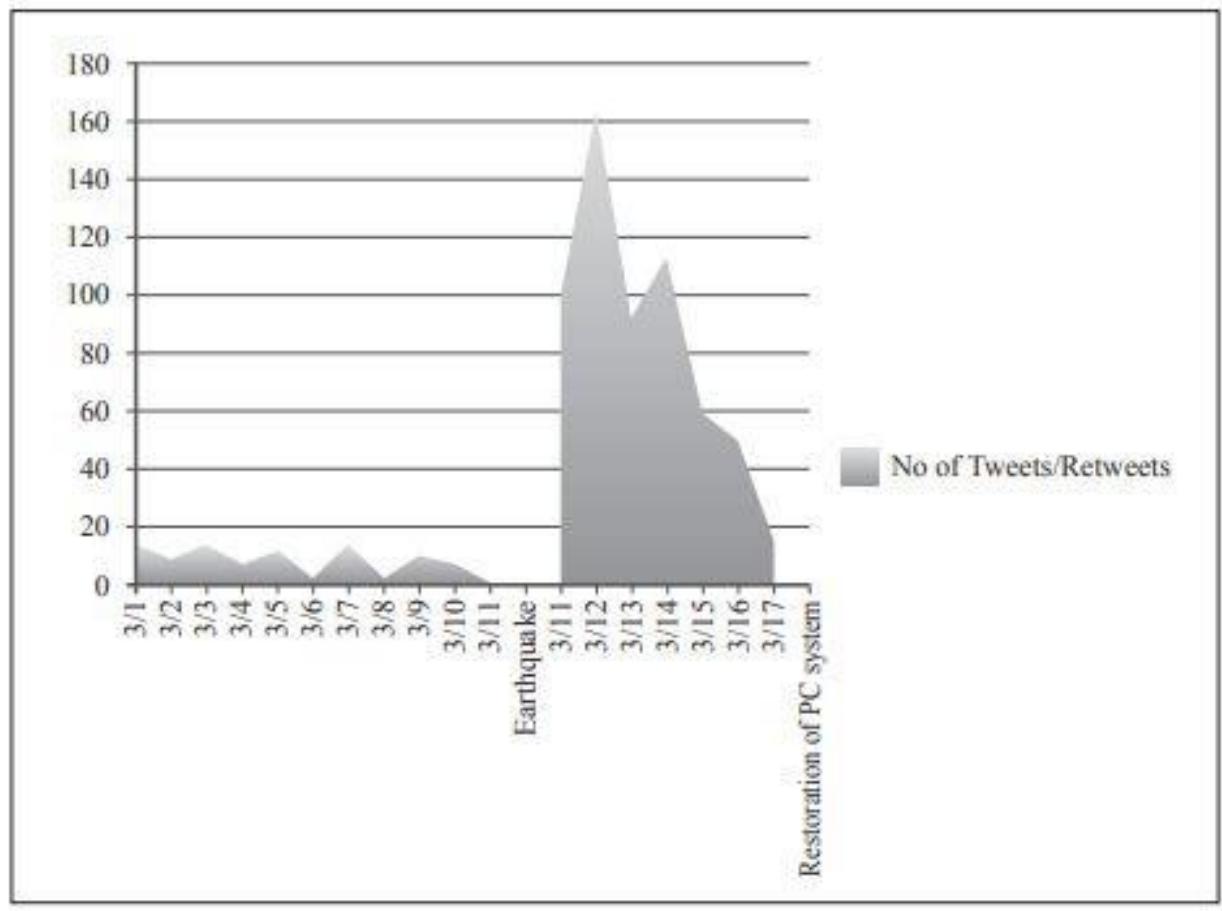

Figure 2.2: Number of Tweets and retweets March1 - March17, 2011 from[15]

In [15] the role of social media is discussed during small disruptions caused by the Japan Earthquake of 2011. Heavy communications made communication difficult. Because of power outage, radio and television also became unusable. The primary communication was on cell phone media access. Twitter among them became a primary tool to create personal networks and gather information. It allows people to keep in touch with theiracquaintances.

The paper presented an analysis of the tweets and re-tweets of the account tsukubais. Which is the Information Sharing center for the city of Tsukuba, Japan. Figure 2.2 shows the analyzed data.

The figure was obtained from data collected from March 1 to March 11, 2011 from Tsukuba Information Systems Department Twitter Account. It is observed that the number of tweets increase sharply after the earthquake and the frequency is continuously higher than the daily number of Tweets preceding the earthquake. 
In Table 2.1 we see the frequency of the terms that was relevant to the Twitter platform.

4.1.

\begin{tabular}{ll} 
High frequency terms in Tweets in relation to the & Count \\
disaster and measures & \\
\hline Transportation (ie. tx, schedule, operation, bus) & 137 \\
Calling out to people (ie. please help, everyone) & 118 \\
Terms indicating time (ie. now, present situation) & 102 \\
Information on water (ie. water supply) & 77 \\
Information in electricity (ie. outages, schedule) & 46 \\
Expression of gratitude (ie. thank you) & 44 \\
Expression of cooperation & 25 \\
Tweets by a Tsukuba city council member & 15 \\
\hline
\end{tabular}

Table 2.1: Frequency of terms that are relevant to the disaster and measures taken from [15]

The Table shows the high frequency of terms used in the disaster in Tweets. Transportation was the most used, followed by contacting relatives and friends and updating the present situation.

The author in this paper chose to do an analysis of twitter usage in the Japan earthquake and how it helped the victims. However, the paper does not show a comparison and analysis of different platforms used at that time.

Palen in [26] focused in the area of research called crisis informatics, which examines the technical, social, and information aspects of disasters and crises. The results of the research activities indicate policy change, innovative technology design, and new theory about social interaction in disaster events.

According to the paper, during the Great Japan Earthquake traditional media and websites could not provide information for the vast majority of victims. Twitter played a major role in disseminating information during the disaster in many communities. Twitter accounts that had local newspaper and local radio and television in the disasters were followed by many. 
Apart from the emerging organizations that come together during a crisis and dissipate after the situation is roughly under control, there are expanding organizations. These groups also use social media tools to give support during a disastrous event but are more structured and have an ongoing presence in different scenarios. During emergency events, these groups can easily take in and organize more volunteers into theirteam.

In 2011 Virtual Operations Support Teams (VOSTs) were conceived. These teams are integrated by "trusted agents" that can manage an enormous quantity of citizen-reported information and implement immediate action for emergency operations. Their goal is to connect emergency management with virtual volunteers mostly by monitoring social media and communicating with the involved community.

From the papers discussed here, we can see very few research has been done in related to social media use during disasters. However, they show an importance of such an analysis. Furthermore, there has been not a multi-platform analysis of any disasters so far. A major part of the reason is the lack of data.

\subsection{Our Contribution to a Disaster Analysis}

Even though there have been studies done on social media use on disasters, we were unable to find any studies which does a comparison or aggregated analysis utilizing the data gathered from multiple different platforms. The main reason behind the lack of such analyses is the difficulty of gathering data form numerous different platforms, especially with the increase of privacy and restrictions free source of data. For our work, we propose the aggregation of disaster related data from multiple different social network platform to do a comparison and 
furthermore, do analysis on the aggregated data to gain better insight into how to efficiently distribute limited disaster relief resource including volunteer efforts and timing critical information. We further propose a method for utilizing the gathered data for creating an automated bot that is able to gather information automatically from the disaster afflicted and communicate with them both experienced and casual volunteers.

Data collection. One of the major problems in the analysis of a disaster is the collection of data. We were able to collect enough data with the help of volunteer groups to do a multiplatform analysis. In most studies data was collected from a single platform. For example, in [15], the data was collected only from twitter. Moreover, other studies used case studies like in [14]. We were able to collect data from all four platforms that were used during the earthquake. It was possible because we were familiar with multi-technologies. We used social computing techniques to understand the ecosystem that was emerging. We were involved in real time with the volunteers that were helping and contributing to the victims. Therefore, we knew where to collect the data from and how. We wrote several programs using existing APIs and integrated them to collect the data from the different platforms.

Big Data. A part of the process was the handling of big data. Large scale data was collected from the four different platforms. There has been various work done regarding the use of data mining for post disaster management $[12,21,22]$. These works usually involve some kind of text analysis using the content generate by users of a disaster affected region. In our research, we have focused on analysing the relation between the content created by disaster affected users of different platforms and the analysis on the way these users utilize these platforms. As we were involved in the process we were able to determine where to collect the data from for analysis. From Twitter, we were required to pay for the huge amount of data that we required. 
The data obtained was in JSON (Javascript Object Notation) format. We extracted the required information from the file using scripts. Furthermore, we created scripts using the Facebook graph API to collect all the related data from the Facebook groups. We then further filtered the data through Python scripts. Similarly, we collected the Slack and Github data. We then categorized the data into number of posts, number of groups. The data was furthered filtered to specify the time period we needed.

Analysis of Different Platforms. Upon collecting the user data from different social media platforms, we analyzed the data to find out any underlying pattern present. This analysis involved doing the comparison of the different platforms in regard to the number of posts, the number of groups created and the activity of people on each platform. This information would be useful for disaster volunteers as they will be able to better focus the limited resources they have available to the platforms that would be better suited for the type of information they require. According to our knowledge, this is the first such research comparing the use of different social media platforms during a natural disaster. In previous studies there were one platform focused mainly twitter. For example, in [17] they analyzed the Twitter in the 2011 Thai flood. In [15] they analyzed the Twitter in the Japan Earthquake. Again, [41] analyzes Twitter uses during crisis. Our focus however is much broader as it compares different platforms.

Survey Conduction for further Analysis. Furthermore, we conducted a survey of social media users to figure out what kind of help they required or wanted from the social media platforms. We analyzed the survey to have a better perspective of the people. From the survey, we were able to separate and distinguish the types of help that people used the social media for. Previously, there were case studies of the different types of help during a crisis $[13,23$, 
34], however in our case we identified the different ways people used the different social media platforms that were never examined in detailbefore.

Design and implementation of a Twitter Bot. During the Earthquake, we were involved in helping the victims with the use of social media. This helped us to have a better understanding of how the platforms were used. We created a real time Twitter bot that helped the volunteers who were helping the victims. This created a new platform for using the social media in a new and automated way. The volunteers joined with us in using the bot to help them better spread information. This new approach is interesting because using of bots in disaster time can help a lot of people. Studies conducted on disasters had not explored this area. [14] gives a detailed description of all the different types of online and other media based platforms used during natural disaster. However, the use of automation bots for information dissemination was not mentioned in any year of the disasters. Usually bots are used as alerts during a disaster. [19] In this case the bot was used in a different way to help volunteers spread news.

Effective utilization of casual users as volunteers. Previous studies have discussed the importance of crowdsoucing in disaster management [11]. We observed a new use and need of volunteers in this earthquake. Because of various social media platforms, we saw the spread of fake news spread in the social media sites. This prompted a group of volunteers to gather on Slack and combine to create a group on Twitter(\#verificao19s). The goal of the group was to evaluate the news and post what was true. We worked with this group of volunteers to help the victims. With our knowledge of the social media computing, we were able to help them in a structured way. This crowd sourcing help is a new process we identified that arose from a need to fight fake news. 


\section{Chapter 3}

\section{Methodology}

The aim of the study is to analyze the role of different social media platforms and new use of technologies during natural disasters. During the recent Mexican Earthquake, we examined and evaluated the different platforms used mainly Slack, Github, Facebook and Twitter. We collected the data from right after the day after the earthquake on September 19, 2017 upto one month. We then analyzed the trend and did an analysis. We further conducted a survey to see people's opinion and reaction to technology use in the time of crisis. We then did a study of the survey data and presented our findings.

\subsection{Research Questions}

To provide a broader lens of how digital volunteers use different technologies during a natural disaster, we study how people used social media platforms and digital tools during the 7.1 earthquake that affected Mexico on September 19th, 2017. In line with guidance from the social computing community on best practices to investigate the use of multiple technologies [4], this study asks two overarching research questions about multi-platform usage in a natural disaster: 
- RQ1: How did people use different socio-technical platforms in Mexico's September 19th earthquake?

- RQ2: What type of help did people provide during Mexico's September 19th earthquake and how did this relate to the different socio-technical platforms they decided to use?

We additionally take an important step to also investigate the type of help that different technologies collectively facilitated during a natural disaster. In other words, we investigate the type of help that people conducted, and associate this with the type of technologies such individuals used. For this purpose, we conduct a qualitative and quantitative analysis data analysis and surveys. to understand people's usage of tech for help in greater depth.and to people who helped in the disaster, and large-scale data with individuals.

The results of our analyses indicate that while Twitter and Facebook were among the first tools used to organize help in the earthquake, specialized work tools such as Slack, were more effective in mobilizing more and longer-term participation from individuals. Twitter and Facebook also provided large value for specialized tools like Slack and Github. More specifically, we observe that posts on Slack or projects on Github containing mentions to Facebook or Twitter were generally more valuable in terms of the engagement from people that the content triggered. For instance, Github projects that mentioned Facebook or Twitterin them had a larger number of individuals participating in the project and a larger number of contributions that Github projects that did not contain links or mentions to Facebook or Twitter. However, we find little evidence that posts on Twitter or Facebook with links to Slack or Github had provided direct value to the communities on Twitter or Facebook. Moreover, we observed that the individuals who utilized specialized platforms such as Slack or Github tended to help in a disaster in a new way, primarily to create new technology. These 
individuals were aware that their technology would likely not be adopted by victims of the disaster, but it was important for them to create a culture of prevention. Individuals with this longer-term vision of their aid were also the ones that used specialized tools the most, and who participated the most in online interactions.

\subsection{Data Collection}

To obtain a descriptive assessment of how different technologies were used in Mexico's massive earthquake, we collected user data from different platforms and studied people's participation over time. For this purpose, we first familiarized ourselves with how people helped and used technology during the earthquake by frequently reading relevant news reports. It is important to note that the researchers are native Spanish speakers from Mexico. Through our initial analysis we identified that the main platforms people adopted were: (1) Facebook; (2) WhatsApp; (3) Twitter; (4) Slack; (5) Github; and (6) Snapchat. Next, we focused on collecting one month worth of data from each of these platforms (note however that since WhatsApp and Snapchat did not facilitate collecting user generated data we concentrated on technologies that did).

We collected one month worth of data from each platform, i.e., from September 19th, 2017 (day of the earthquake) to October 19th, 2017. Armed with the data, per platform we examined: (1) the daily number of posts produced related to the earthquake; (2) the daily number of online groups created for the earthquake; and (3) the total number of posts about the earthquake that an individual user generated depending on when the person first started participating. Notice that points (1) and (2) help us to understand different platform usages 
through time; while point (3) further facilitates understanding people's behavior across platforms. Especially as previous work identified that newcomers' start date can influence the type of contributions newcomers make.

- Facebook. We collected data from all Facebook groups and Facebook pages related to Mexico's earthquake. We found them by searching for groups and pages. All the pages that mentioned keywords related to the earthquake in their name or description were selected. These keywords were related to Mexico's earthquake according to news reports. In specific the keywords we utilized were: "sismoMexico" ["earthquakeMexico"], "19S" [abbreviation of September 19th, the day of the earthquake; this term was used to identify the earthquake], "FuerzaMexico" ["MexicoStrong', this term was used to identify activity around the earthquake], "verificado19s"["verified19S", this term was adopted to present verified information during the September 19th earthquake], "ayudaCDMX" ["helpMexicoCity", this term was used to identify help provided during the earthquake], "infoConfiableCDMX" ["verifiedInformationMexicoCity", this term was adopted to present verified information during the earthquake]. Notice that we also used synonyms of thekeywords in our search (for instance a synonym of "sismo" is "terremoto" so we also searched for "terremotoMexico"). Through this process we identified 48 Facebook groups and pages that were created on or after September 19th, 2017. Next, we used Facebook's public graph API to get all the posts and user ids generating the content from these Facebook groups and pages. We considered that a post in this setting was a Facebook post that an individual made in one of these earthquake related Facebook groups or pages; and a group was represented by a particular Facebook group or page. We were able to collect 14,193 such posts. We also collected comments, likes and shares. 
- Twitter. We collected all the tweets relevant to the earthquake from the entire Twitter traffic via Gnip Power Track, a commercial Twitter data provider. We used the same keywords as above to identify relevant tweets. The data we collected consisted of all the tweets and Twitter IDs of the people generating earthquake related content. We considered that a post in this setting was an earthquake related tweet that an individual posted; and a group was represented by a particular hashtag (recent work has highlighted the role of the Twitter hashtag - a short keyword, prefixed with the hash symbol "\#” - as a means of coordinating a distributed discussion within a group of people [39]. We use hashtags as a proxy to identify groups or organizations that emerged on Twitter during the earthquake).

- Slack. People used Slack, a team collaboration tool ${ }^{1}$, to organize the production of tools to help in the earthquake. In specific, people organized around the slack of "Codeando Mexico" [Coding for Mexico] ${ }^{2}$, an open community focused on "developing technology to build a better Mexico" . Coding for Mexico opened its Slack for anyone to join and help build technology for the earthquake. In Codeando Mexico's slack people created different channels (groups) to organize the creation of different tools. These channels all started with the keyword "sismomx" followed by the channel's specific focus. For instance, "sismomxfakenews"was a channel that was focused on developing tools to verify earthquake related information that seemed to be fake. Figure 4.1 presents an overview of Codeando Mexico's slack channel. We collected all the messages along with the user ID of the person who produced the message, of all Slack channels related to the earthquake (52 channels in total). We considered that a post in this setting was a Slack message posted in one of these earthquake related Slack

\footnotetext{
${ }^{1}$ https: //slack.com/

${ }^{2}$ http: //codeandomexico.slack.com/
} 
channels; and a group was represented by a particular Slack channel (as channels hold groups of people who are coming together to communicate on a particular topic or in this case creation of a particular tool).

- Github. People used Github ${ }^{3}$, a popular code sharing platform, to create repositories and share code of tools they built for the earthquake. We first collected the Github repositories of all tools that were created and organized within the Slack of Coding for Mexico by searching for Slack messages metioning any Github links. We alsoidentified relevant Github repositories by identifying any mentions to Github links in the tweets and Facebook posts we collected previously. Through this process we identified 26 Github repositories. For each Github repository we collected its description, IDs of people contributing to the project, and number of commits made (a commit represents the latest changes to [part of] the source code in a repository). We considered that a post in this setting was a commit that an individual made in one of these earthquake related Github repositories. We considered that a group or organization was represented by a given repository (as it represented a group of people coming together to build a particular tool).

Bots: We also created a bot that would interact with the public on Twitter. The objective of the bot was to help the volunteers that were helping the victims by confirming and distributing information on social media. Once a request for some information was made or information of some resources was made, the volunteers would verify the information and post it on a sheet. The bot automatically took information from the sheet and posted on Twitter. If a resource was needed, the bot would ask where is the resource needed. The bot would try to communicate with the public to This helped the volunteers save time to spend more effort on

\footnotetext{
${ }^{3}$ https: //github.com/
} 
verifying information. The description of the bot was "Send us your reports via tweets or DM. We verify them and publish real info. Use us to access reliable and verified information." The link to the bot [3] 


\section{Chapter 4}

\section{R1: Use of different socio-technical platforms}

\subsection{Data Analysis and Results}

The details of the data set we collected are shown in Table 4.1.

\begin{tabular}{lll} 
Platform & Posts & Participants \\
\hline Facebook & $\begin{array}{l}14,193 \text { [posts in Facebook } \\
\text { groups or pages about the } \\
\text { earthquake] }\end{array}$ & \\
& $\begin{array}{l}2,820,400 \text { [tweets with earth- } \\
\text { quake hashtags] }\end{array}$ & 792,665 \\
Twitter & $\begin{array}{l}\text { 28,781 [messages in earth- } \\
\text { quake Slack channels] }\end{array}$ & 347 \\
Slack & $\begin{array}{l}5,491,500 \text { [commits in earth- } \\
\text { quake Github repositories] }\end{array}$ & \\
\hline
\end{tabular}

Table 4.1: Data collected per platform.

Our first research question explores how people used four different technologies platforms during the earthquake. For this purpose, we examined: (1) the daily number of posts published on each platform; (2) the daily number of groups created on each platform; and (3) the activity of people based on when they first started contributing to a given platform.

1. Daily posts. We plotted the number of posts made on different platforms (Figure 4.1). For 
Facebook, we calculated this based on the daily posts published in groups and pages related to the earthquake. For Twitter, it was the daily tweets related to the earthquake. For Slack, it was the daily messages exchanged in different channels related to the earthquake. For Github we took the daily commits made to each of the earthquake related repositories. We used this first analysis as an overview of how active people were on each platform through time.
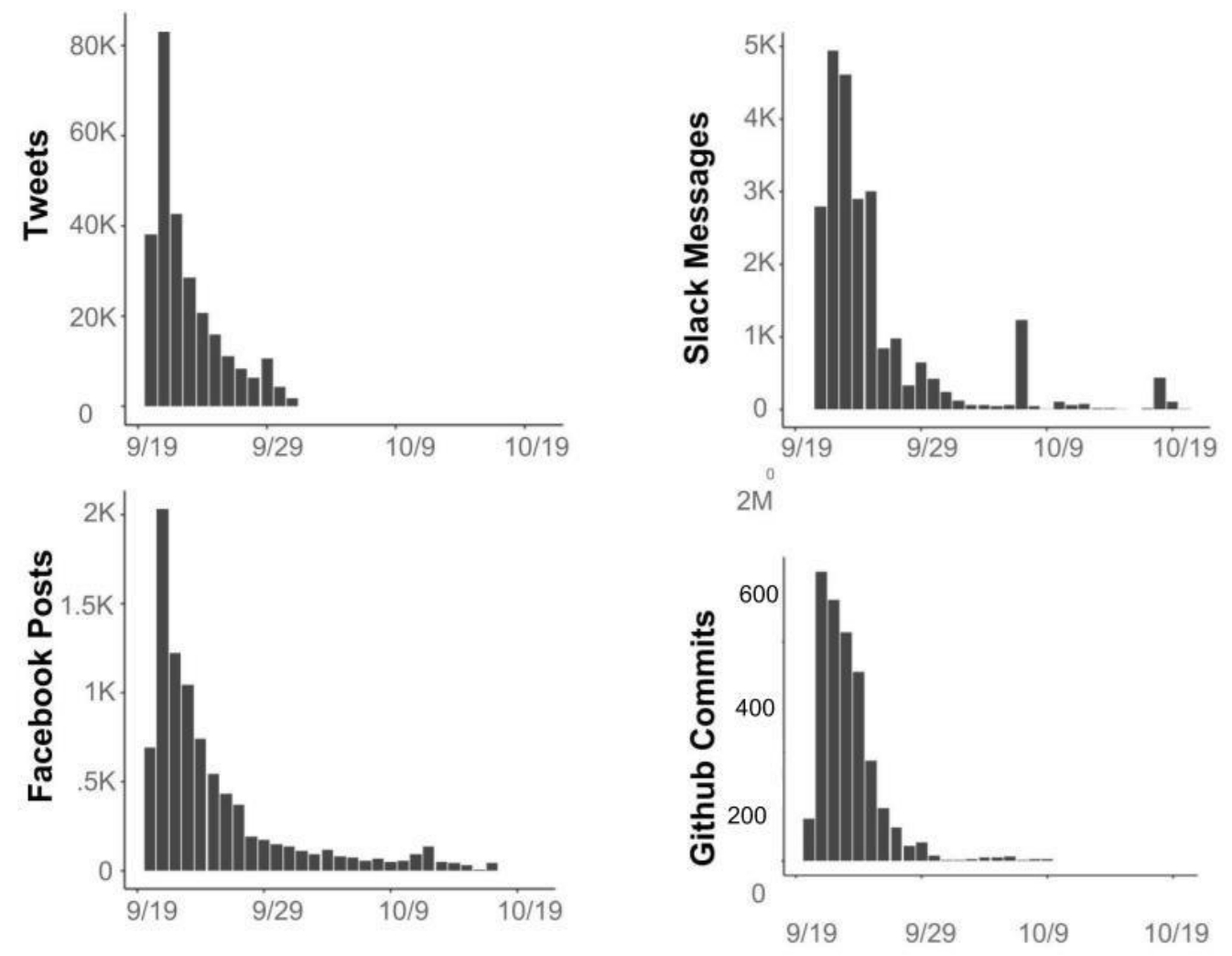

Figure 4.1: Daily number of new posts created across each platform

Fig 4.1 presents the total number of posts generated per platform and the number of people who generated such content. Fig. 4.1 presents the daily number of posts generated per platform. From Fig. 4.1 we observe that for almost all platforms the number of posts decreased overtime. Twitter was the most active during the first few days after the earthquake. The highest peak being on September 20th, 2017, the day right after the earthquake. But the activity on Twitter quickly died out as the days advanced. We see similar patterns on 
Facebook and Slack. People were highly active on both platforms the days immediately after the earthquake. But, gradually stopped participating over time. In Github, we see that although there was not very activity in the immediate beginning, there was a huge high spike towards right after around September 24th. What is particularly fascinating about the platforms is that they show similar patterns of being active towards beginning of the earthquake. Upon inspections of the posts created close to the 1 month anniversary of the earthquake we observed that people were posting information about mechanisms they had adopted to keep safe during earthquakes, help others to keep safe, as well as tools they had built to keep people safe in the long term. Figure 1 presents an example of these posts.

2. Daily Groups. To further inspect people's participation across technologies, we plotted the number of daily groups that people created on each platform (see Fig. 4.2). From Facebook, we counted the number of Facebook groups and pages about the earthquake created each day. From Twitter, we counted the number of new hashtags that people created daily (research has highlighted that Twitter hashtags help cluster people around particular topics [39]. We therefore used hashtags as a proxy to identify topical groups that emerged on Twitter during the earthquake). Notice that we identified when new hashtags related to the earthquake emerged by tracking hashtag usage in the tweets about the earthquake we had collected previously. From Slack, we counted the number of new channels created daily, as channels hold groups of people coming together to communicate on a particular topic (in this case the creation of a particular tool). From Github we counted the number of new repositories created daily (we used repositories as a proxy for groups as repositories illustrate ensembles of people coming together to build specific tools).

Fig.4.2 showcases that across platforms the majority of groups were created in the first 3 days 

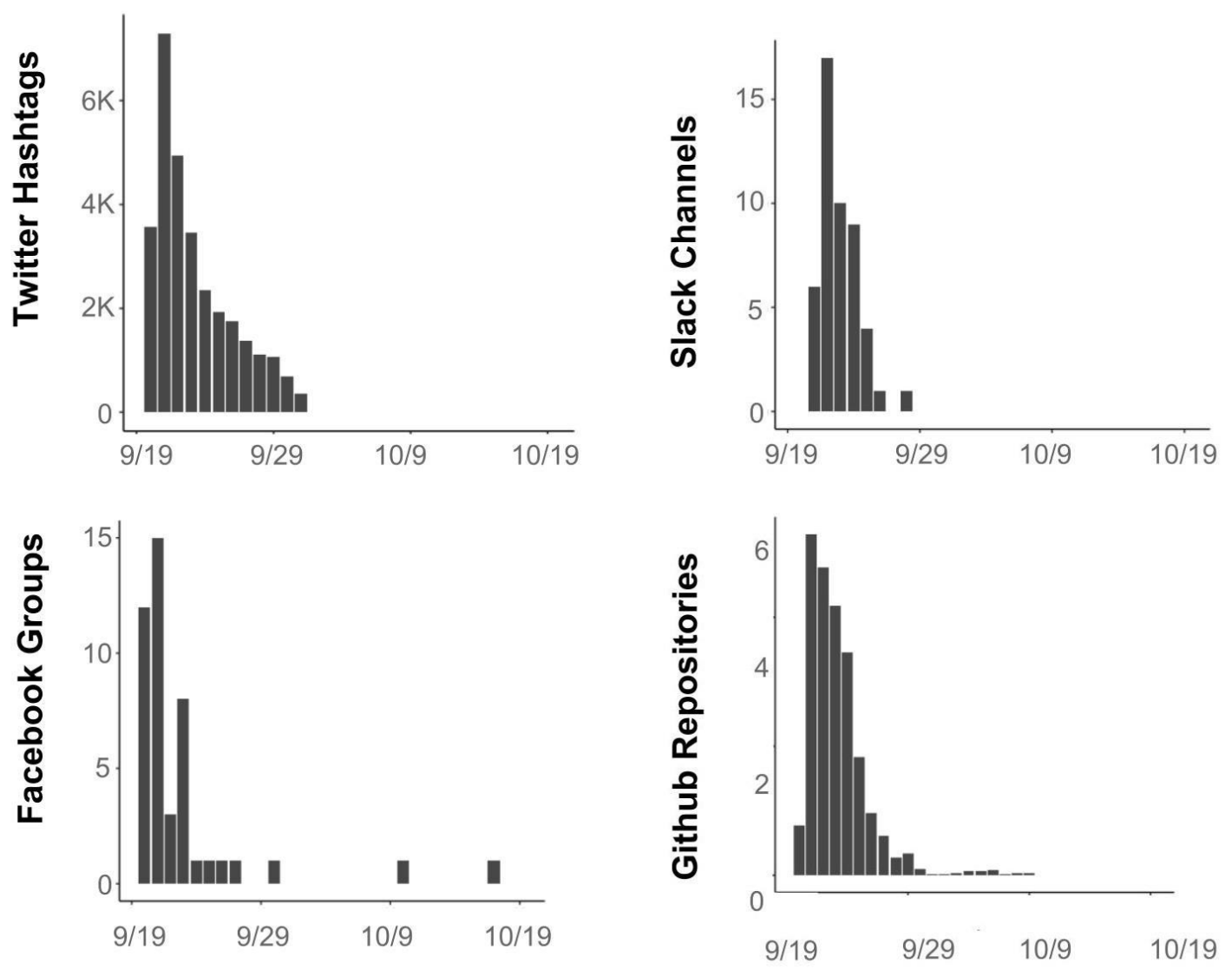

Figure 4.2: Daily number of new groups created across each platform.

and then new groups stopped being created. However, we observe that again on Facebook there was a somewhat continuous creation of groups in the first month. While all other platforms lacked new groups after October 8th, 2017, two new groups were created on Facebook in that time. We see that most of the groups/hashtags were created right after the earthquake. Twitter had a lot more hashtags and kept creating more hashtags compared to the groups of other platforms. All the platforms created groups or repositories towards the beginning.

3. People's Activity Based on Join Date. To better understand how people participated with different technologies we study when individuals started using a particular platform to post about the earthquake and the total number of posts they made on the platform. Previous work had identified that people usually contributed different types of help depending on when they 
joined the rescue efforts. Therefore, this analysis helps us to start to unravel how different platforms were used. In Fig. 4.3 we plot for each person the day they started using a particular platform to post about the earthquake ( $\mathrm{X}$ axis) vs the total number of posts they created on that platform (Y axis). Each point represents a particular individual. We observe that in general across almost all platforms (except Twitter) the most active individuals, i.e., the persons that posted the most content, were the ones that started using the platform within the first 5 days. In Twitter however, we observed another behavior: there were many highly active users who joined seemed to have joined sporadically in the weeks following the earthquake. One of the most active users on Twitter actually joined till October 6th (almost 3 weeks after the earthquake.) Upon closer inspection of such accounts we observed they had the name "bot" in their user-handle and were posting news reports about the earthquake. In other words, these highly active accounts seem to be automated bots that people might have created to help in the earthquake. Such accounts appeared to be posting verified news reports.

Figure 4.3 shows that in Twitter most users remained active throughout the period of two months. Whereas, in Slack people were most active during the month of September and was inactive during October. The Facebook chart shows that users were more active towards the start. In Github, there were less users than other platforms and they were active towards the start.

We further plotted the number of active users on different platforms. From Facebook, we collected the data on members active each day. From Twitter, we collected the number of users that tweeted each day. From Github, we collected how many days users exchanged messages.

Table 4.2 shows a comparison of the mentions of different platforms in a particular platform. This gives us better picture of how the different platforms were related. As this relationship 


\section{People's Start Date and their \\ Total Number of Posts}
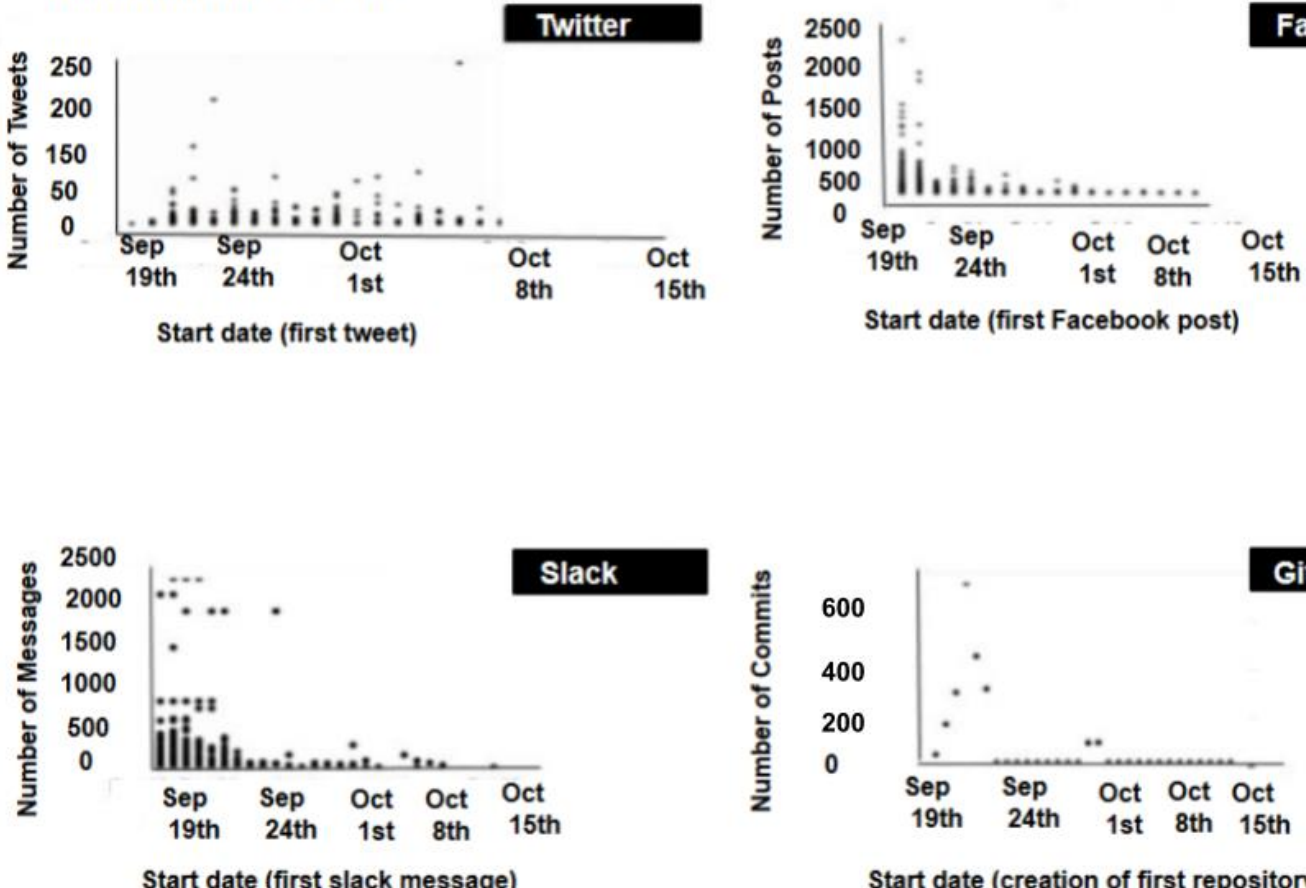

Figure 4.3: The date people started posting about the earthquake vs the number of posts they generated across platforms.

\begin{tabular}{|l|c|c|c|c|}
\hline & Facebook & Twitter & Slack & Github \\
\hline Facebook & - & 19 & 0 & 0 \\
\hline Twitter & 2115 & - & 0 & 1 \\
\hline Slack & 70 & 287 & - & 766 \\
\hline Github & 7 & 25 & 17 & - \\
\hline
\end{tabular}

Table 4.2: Mentions of platform in per platform.

has not been analyzed in previous works, this result can show a trend of how the different platform are being used. We see that Facebook has some mentions of Twitter and none of Slack or Github. Similarly, Twitter has mentions of Facebook, however by a wider margin. It has little or no mentions of Github or Slack. Slack on the other hand, has mentions of all other platforms with Twitter and Github being more prominent. Github also has a some mentions of other platforms primarily because Github was used to build applications that was used by the other platforms. 


\section{Chapter 5}

\section{R2: Type of help people provide}

To understand the type of help that people provided and how this related to the type of technologies used, we prepared a survey. We designed the survey to elicit information from people about the types of technology used; type of help provided; and people's perspectives on the impact of their help. We also included additional questions in the survey to collect demographic data and more information about people's background (where they were from, their relationship with earthquake victims.) With respect to the help they provided, people were first asked to report via open-ended questions:

- How they helped earthquake victims in general.

- How they used technology to help earthquake victims.

- The impact they believe their help had on earthquake victims

We then asked a series of Likert questions probing how much they had used particular technologies to help during the earthquake. Specifically, we questioned people about how much they utilized the following main technologies: a) Facebook; b) Twitter; c) Slack; d) Github; e) Whatsapp; f) SnapChat. Participants also responded via Likert questions about how 
much they felt their help had impacted earthquake victims.

We further asked individuals to provide open-ended descriptions of the biggest challenge they experienced when trying to use technology to provide help; and finalized the survey by asking persons to provide two open-ended descriptions of guidelines they believe people should follow when using technology to help in an earthquake.

\subsection{Recruitment and Analysis}

Participants were recruited from the main technological platforms used in the earthquake. We posted invitations to our survey on the different Slack channels and Facebook groups. We also posted invitations to our survey on Twitter using earthquake related hashtags.

In total 356 individuals completed our survey. Participants were distributed across Mexico (88.86\%), and we also had several people from outside Mexico who participated in the help (11.14\%). The median reported age was 25 (ranging from 15 to 65.$) 22.29 \%$ of participants reported they had personally been affected by the earthquake (some individuals even reporting to have lost a family member); $39.3 \%$ reported they had friends and family affected by the earthquake; $21.11 \%$ reported they had some type of connection with earthquake victims; and $32.26 \%$ reported no connection to anyone affected by the earthquake.

We coded all open-ended responses iteratively using a qualitative coding approach. We coded the following participant responses for themes to understand the type of help that individuals provided during the earthquake:

- How they helped earthquake victims 
- How they used technology to help earthquake victims.

- The impact they believe their help had on earthquake victims

- How they helped earthquake victims

- How they used technology to help earthquake victims.

- The impact they believe their help had on earthquake victims

We repeatedly recorded data to accommodate emerging themes. Survey responses were initially coded by one of the researchers who established a code book with categories and examples. The code book was reviewed and revised iteratively by the research team. After coding was finished, we hired 3 Spanish-speaking, college-educated workers from Upwork to categorize all of participants' responses independently. First, we asked two coders to categorize each of the responses using the topics listed in 5.1. We asked the coders to pick the topics that best represented each response. Coders could pick more than one topic per response. We then asked the third coder to label the responses upon which the first two coders had disagreed. We then used a "majority rule" approach to determine the topics for those responses.

From these responses, we were able to distinguish the type of help people provided from the different platforms. The below figure shows a chart depicting the types of help.

From Fig 5.1 we see that there were 7 main categories of help in the platform that we were able to identify. The categories were Networking, Petitions, Communications, Information Distribution, Data analysis, Build Technology and Donations. The bars show the comparison of each type of help. 


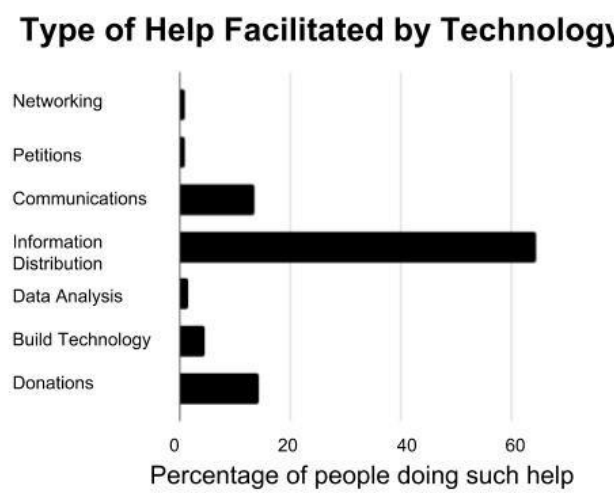

Figure 5.1: Type of Help

Networking. This category is about using technology to help users meet new people, establish stronger relationships. For example, this category is about using technology to connect people with individuals that could help them. Networking was not mostly used among the social media platforms during the crisis.

Petitions. This category is about using technology to help users meet new people, establish stronger relationships. For example, this category is about using technology to connect people with individuals that could help them. Petitions was also not used in the social media platforms during the earthquake.

Communications. This category is about using technology to communicate, converse, contact, coordinate with each other. People that use technology to communicate used it to call their family and friends, in order to know what was going on with them. Communications was used a significant amount in the social media platforms. It was mainly done through Twitter. Information Distribution. This category is about using technology to read, visualize, search for, distribute or post general information. Information distribution was the most used and important during a disaster. People used social media to spread information about their situation and what help they needed. It was mostly done through Twitter as it is easier. Data Analysis. This category is about using technology to analyze data with the information 
related to the earthquake. A small part of the social media platforms was used in data analysis. It was done mainly in Slack.

Build Technology. his category is about using technology to create new technology that would help in the earthquake situation. Building of technology is a new concept that emerged within the few years. During the crisis building of technology was also used to better help the victims through Slack and Github.

Donations. This category is about using technology to make donations to the people affected by the earthquake or to give money to people in need. Donations was done significantly in social media platforms. Facebook was the main platform for donations. Twitter was also used in this regard.

\subsection{Results}

How they helped earthquake victims: Of our 356 participants, $63.34 \%$ reported that they helped in the 19s earthquake. Among the individuals $3.52 \%$ were confused about their level of assist in the crisis. They invested a median of approximately 20 hours in helping during the earthquake crisis (ranging from less than an hour to almost 3 months). About 5.28\% were unsure of how many hours they invested.

How they used technology to help earthquake victims: Of our 356 participants, $56.03 \%$ reported that they used technology to help during the earthquake. When asked about their technology usage $36.67 \%$ answered a lot, $14.96 \%$ said a moderate amount, $4.4 \%$ said little and $5.28 \%$ replied non-through technology. In a question to describe how they used the technology, most replied by distribution of information. $21.86 \%$ of the people said they helped verify information. They felt the need to verify information because of misinformation being 
spread around in this time could waste resources and time.

The impact they believe their help had on earthquake victims: The participants categorized their contribution into categories such as networking, petitions, communication, information distribution, data analysis, building technology and donations (detailed in Table 1). Figure 4 shows a comparison of the different categories. Participants felt like they contributed more in information distribution. Some also contributed a significant amount to communication and donation through technology.

\subsection{Bots in Disaster Management}

A new approach to the multi-social platform was the usage of bots. The volunteers gathered to help verify information. Usng the Twitter, API, Flask and Python code we created a bot. This bot was created from a multi-social approach. Volunteers on slack gathered to discuss new ways to help and came up with the idea of bots. We created a bot in Github. People used the bot from the Github. A sample of the code is shown below.

The volunteers would gather information and verify it. Then they put those in a spreadsheet. The bot collected that information and posted it on Twitter. A diagram of the process is show in Figure 5.3. 


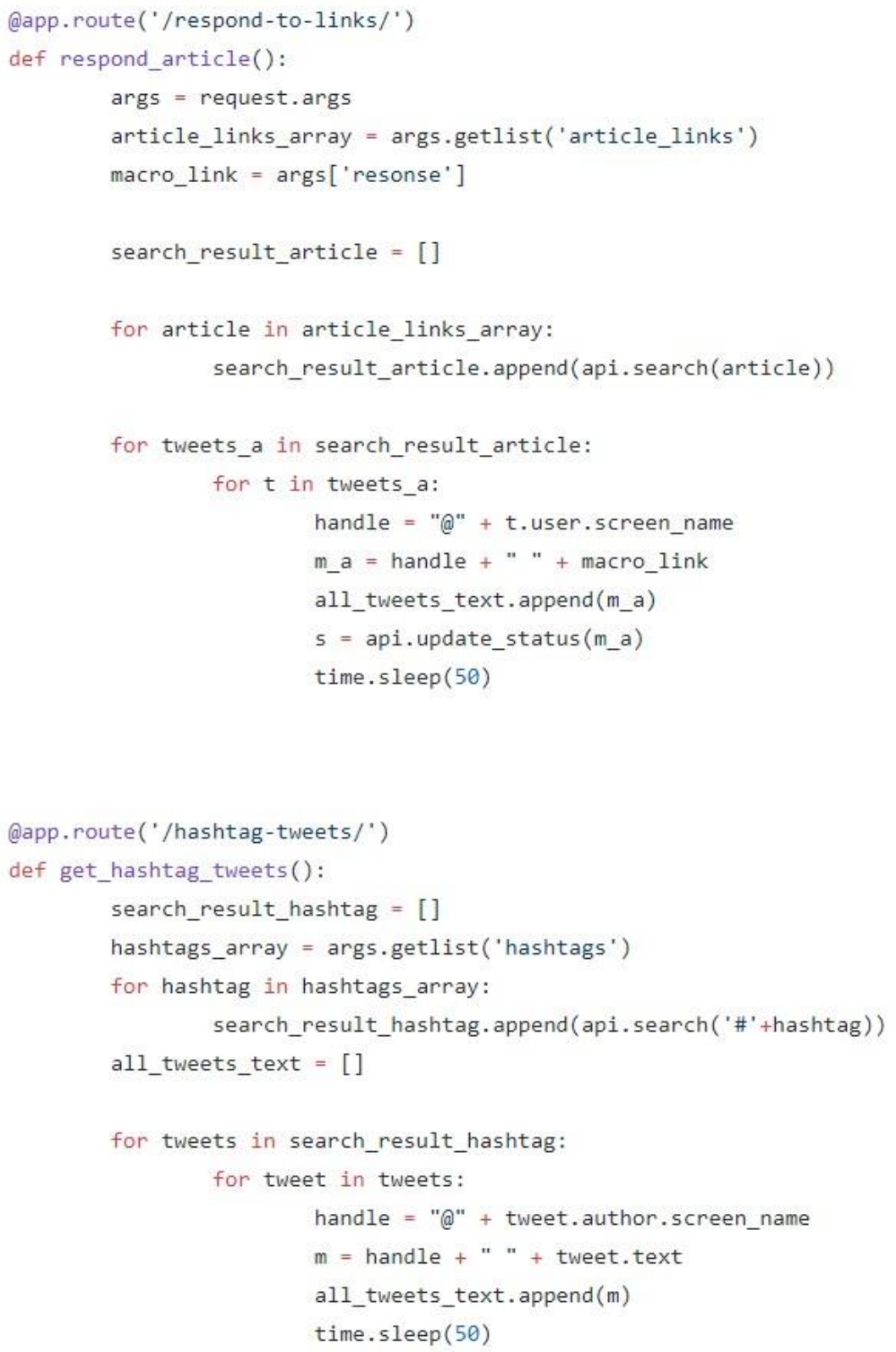

Figure 5.2: Parts of Twitter bot code 


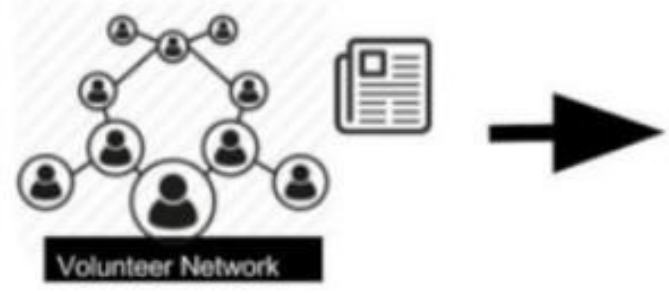

1. Volunteers report news.

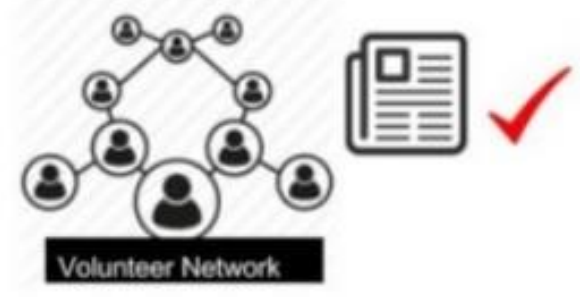

2. The network of volunteers verify the news reports.
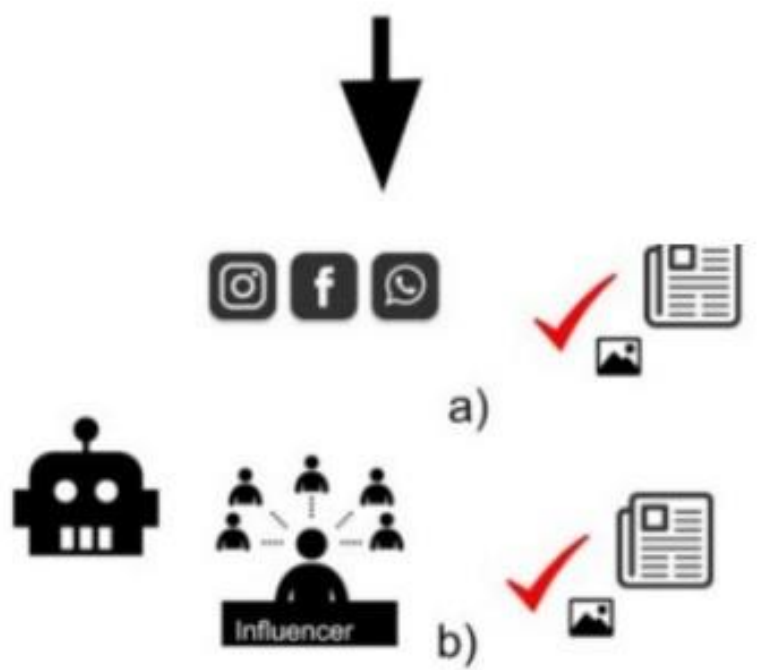

a)

b)

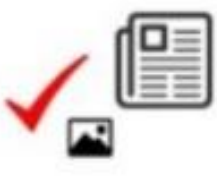

3. Bots take the verified citizen reports and distribute: a) on social media.

b) with influencers who can decide what to post.

Figure 5.3: Bots used during the Earthquake 


\section{Chapter 6}

\section{Discussion}

Although, the development of new technology during the earthquake in Mexico in 2017 may not have been as direct as volunteering on site or donating resource, it was however more persistent and it is more focused on the future since it helped not only during the emergency situation but it will continue to help raise awareness about disaster prevention and aid organizations. This is a brand-new step in the social media volunteering spectrum. Casual volunteers or people concerned about the disaster, who may not have been able to volunteer or donate directly due to lack of opportunity can still help the affected people and contribute to the relief effort with the help of social media platforms by coordinating the volunteers, directing resources to the most affected by providing indirect information with their online activity, interacting with bots to provide aggregated analysis to the volunteers and by disseminating information directly. The usefulness of the social platforms in these regards are evident from our data analysis.

Through our process we collected data from different sources, handled and filtered large amounts of data, analyzed the data to get a picture of the use of different platforms, 
participated in real time to identify and introduce new tools in disaster situation, identified the importance of crowdsourcing during this time and surveyed to find out the different ways people helped the victims during this time.

Moreover, In this chapter, we discuss the main points of our analysis using the previously described themes that tend to appear across all social movements. These themes are, framing processes, mobilizing structures, and opportunity structures.

Framing Processes. By framing process, we mean the procedure through which the components constitutive of an edge are amassed and coordinated in an important manner;

Reasonably, framing includes the association, or joining together, and coordination of issues, occasions, encounters, and social things, including strands of one or more belief systems, with the goal that they hang together in a moderately incorporated and important design. It constitutes a sort of aggregate bundling gadget that collects and groups cuts of appropriated, watched, experienced, and additionally recorded 'reality" with the goal that a specific occasion, pattern, or issue is surrounded one way.

They may include actual events or happenings such as disaster or auto accidents or pseudo-events [5].

Through our analysis, we observed 3 key aspects of technology use by people during disaster. We observed that people, (1) use technology as a method to provide their contribution during the disaster; (2) used different platforms in different ways; and (3) tried to find a new way to help people with technology

Our results indicate that people on average spent a big amount of their time to try to help the victims. The use of technology was a big part of it. 
Data obtained from the platforms showed the different uses of the different social media platforms. This very important in understanding the use of social media utilization in disasters. No other studies so far have a comparison of the different social platforms. For instance, in [15], the information was gathered just from twitter. Besides, different examinations utilized contextual investigations as demonstrated in [14]. Again, in [17] they conducted analysis on data obtained from Twitter in the 2011 Thai flood. Our work on the other hand, has start the process of better understanding of the usage of different platforms.

Although all of the platforms analyzed in this work were used by people during disasters, we found that some platforms were used more often than others while some other platforms were used more extensively. People seemed to prefer Twitter over other platforms in terms of the frequency of its use. Having the most users, it dominated over other platforms in sheer volume of use as well. It appeared to be a easier method for people to distribute information, which was the biggest use of technology. However, each platform was active in different ways. What was fascinating being that Github was used at a small interval of time but in a huge amount per user. It has the least number of users among the platforms analyzed but the contribution was per user was larger than any other platform.

Where Twitter and Facebook was used for distribution and collection of information, Slack and Github was a medium for building tools and finding better ways to improve the distribution. New tools were created to ease the distribution of information in a new way and can have a longer lasting impact in the long run compared to on the moment information dissemination and coordination.

This is a new concept that arose from the need of bots in volunteer crowdsourcing. Usually bots are used as alerts during a disaster[19]. In this case the bot was used in a different way to 
help volunteers spread news.

Mobilizing Structures. The mobilizing structure is the social communities and all assets important for popular mobilization, which for this situation comprises of online networking as the quickest and least expensive approach to assemble. These two viewpoints are important to the development of social developments[20].

We witnessed that the general people, either from Mexico or an amount from outside of Mexico mobilized on Twitter and Facebook in order to help and contribute their part. A big part of mobilizing in social media platforms is the ease of accessibility. People understood that not all of them could be present to help the victims. However, they wanted some way to help their relatives and friends that were affected by the earthquake. The ease of use of these platforms and the extensive familiarity of them made the people more inclined to use them for helping with the disaster efforts.

Past examinations has talked about the significance of crowdsourcing in catastrophe administration. [11] We watched another utilization and need of volunteers in this seismic tremor. As a result of different web based life stages, we saw the spread of phony news spread in the internet based life locales. This incited a gathering of volunteers to assemble on Slack and join to make a gathering on Twitter(\#verificao19s). The objective of the gathering was to assess the news and post what was valid. We worked with this gathering of volunteers to encourage the casualties. With our insight into the online life figuring, we could help them structurally. This group sourcing help is another procedure we distinguished that aroused from a need to battle counterfeit news.

To build on top of that, in this work we facilitated another part of the users for mobilizing in Slack and Github in order to find a new approach to the use of technology. The users in this 
case were mainly volunteers and programmers. A crucial part of this mobilization was the need to verify and make sense of the huge amount of information being spread during the crisis. They felt a need to find a better way that would help rather than create more panic or distribute misinformation.

Opportunity Structures. Opportunities vary in different parts of society for establishing social contacts or relationship with persons who are similar or different [1]. It is a lattice which connects private attributes to the social and social shots and decisions which are open to a person all through their lifetime [24].

We directed a review of online life clients to make sense of what sort of assistance they required or needed from the internet based user platforms. We investigated the survey to have a better understanding of view of the users. From the study, we could have isolated and recognize the kinds of assistance that individuals utilized the web based platforms.

Beforehand, there were contextual investigations of the different kinds of assistance amid a crisis[13, 23, 34], but, for our situation we recognized the distinctive ways individuals utilized the different web based platforms that were never analyzed in detail before. Our study revealed that the technology was used in networking, petitions, communication, information distribution, data analysis, building technology and donations. Among them, distribution of information was the most common. The likely explanation for this is distribution of information is important during a natural disaster. Because it is easier to spread information quickly through social media, it is the most popular category. It is important to know what is needed and where, if people need rescued or help. This is made easier with social media. Twitter showed the most active in this case. Social platforms are very useful in such a case as most people have access to it now-a-days. 


\section{Chapter 7}

\section{Limitations and Future Work}

We faced some limitations and difficulties conducting the research. First, the data collected was for one month. The analysis would be better with more data. Another limitation for our work is the ability to determine which groups are related to the earthquake and to obtain posts that people posted related to the earthquake. There is a possibility people can have posted related to the earthquake that we were not able to identify.

For further study, we plan to do a more detailed analysis of the different platforms. We can analyze the types of posts people made and why. Moreover, we can do a broader form of the survey so that we get more accurate classifications. Furthermore, we plan to apply the same analysis to other forms of disasters. We hope that we can relate the social media use in different disasters. We hope the structured form of help and understanding the types of help people need will help in future disaster situations. Moreover, we can differentiate the different geological areas and compare how different way social media platforms are used. 


\section{Bibliography}

[1] Networking and Belonging: Opportunity Structures, Rational Choice Exchanges, and the Sociology of Emotions. Springer New York, New York, NY, 2008, pp. 195-222. "https://doi.org/10.1007/978-0-387-76522-8_8".

[2] Mexico hit by powerful 7.1 magnitude earthquake, killing more than 225, 2017.

[3] Sismo bot sismobotmexico, 2017.

[4] An, J., Kwak, H., Mejova, Y., De Oger, S. A. S., And Fortes, B. G. Are you charlie or ahmed? cultural pluralism in charlie hebdo response on twitter. In ICWSM (2016), pp. 2-11.

[5] Benford, R. D., And Snow, D. A. Framing processes and social movements: An overview and assessment. Annual Review of Sociology 26, 1 (2000), 611-639. https: //doi.org/10.1146/annurev.soc.26.1.611.

[6] Chan, J. C. The role of social media in crisis preparedness response and recovery.

[7] Davenport, S. W., Bergman, S. M., Bergman, J. Z., And Fearrington, M. E. Twitter versus facebook: Exploring the role of narcissism in the motives and usage of different social media platforms. Computers in Human Behavior 32 (2014), 212 - 220.

[8] EXPANSION. "as puedes usar la tecnologa para comunicarte y ayudar tras el sismo en mxico". CNN espanol, Sep 2017. http://cnnespanol.cnn.com/2017/09/19/ usa-la-tecnologia-para-comunicarte-tras-el-sismo-en-mexico/.

[9] EXPANSIN. "el sismo en mxico y las redes sociales, entre la eficacia y los rumores". CNN Espanol, Sep 2017. http://cnnespanol.cnn.com/2017/09/23/ el-sismo-en-mexico-y-las-redes-sociales-entre-la-eficacia-y-los-rumo

[10] FUNAM. "desastres naturales, problema cada vez ms frecuente, coinciden expertos". FUNAM, Oct 2017. http: / /www. fundacionunam.org.mx/gracias-a-ti/ desastres-naturales-problema-cada-vez-mas-frecuente-coinciden-experto

[11] Gao, H., Barbier, G., And Goolsby, R. Harnessing the crowdsourcing power of social media for disaster relief. IEEE Intelligent Systems 26, 3 (May 2011), 10-14.

[12] Hashimoto, T., Chakraborty, B., Kuboyama, T., and Shirota, Y. Temporal awareness of needs after east japan great earthquake using latent semantic analysis. 200212. 
[13] Houston, J. B., Hawthorne, J., Perreault, M., Hae Park, E., GoldStein Hode, M., Halliwell, M., E. Turner McGowen, S., Davis, R., Vaid, S., MCElderry, J., AND A. GrifFith, S. Social media and disasters: A functional framework for social media use in disaster planning, response, and research.

[14] Julia Daisy Fraustino, Brooke LiU, Y. J. Social media use during disasters: a review of the knowledge base and gaps. National Consortium for the Study of Terrorism and Responses to Terrorism.

[15] KaIgO, M. Social media usage during disasters and social capital: Twitter and the great east japan earthquake. 19-35.

[16] Kaufhold, M.-A., AND Reuter, C. The self-organization of digital volunteers across social media: The case of the 2013 european floods in germany. Journal of Homeland Security and Emergency Management 13, 1 (2016), 137-166.

[17] Kongthon, A., Haruechaiyasak, C., Pailai, J., And Kongyoung, S. The role of twitter during a natural disaster: Case study of 2011 thai flood. In 2012 Proceed- ings of PICMET '12: Technology Management for Emerging Technologies (July 2012), pp. 2227-2232.

[18] Kuttschreuter, M., Rutsaert, P., Hilverda, F., Regan, Á., Barnett, J., And VERBEKE, W. Seeking information about food-related risks: The contribution of social media. Food quality and preference 37 (2014), 10-18.

[19] Liu, S. B., Bouchard, B., Bowden, D. C., Guy, M., and Earle, P. USGS Tweet Earthquake Dispatch (@USGSted): Using Twitter for Earthquake Detection and Characterization. AGU Fall Meeting Abstracts (Dec. 2012), S21A-2431.

[20] LOPES, A. R. The impact of social media on social movements: The new opportunity and mobilizing structure.

[21] Mandel, B., Culotta, A., Boulahanis, J., Stark, D., Lewis, B., And RoDRIGUE, J. A demographic analysis of online sentiment during hurricane irene. In Proceedings of the Second Workshop on Language in Social Media (Stroudsburg, PA, USA, 2012), LSM '12, Association for Computational Linguistics, pp. 27-36.

[22] Mandel, B., Culotta, A., Boulahanis, J., Stark, D., Lewis, B., And RoDRIGUE, J. A demographic analysis of online sentiment during hurricane irene. In Proceedings of the Second Workshop on Language in Social Media (Stroudsburg, PA, USA, 2012), LSM '12, Association for Computational Linguistics, pp. 27-36.

[23] Nagar, S., Seth, A., ANd Joshi, A. Characterization of social media response to natural disasters. In Proceedings of the 21st International Conference on World Wide Web (2012), WWW'12 Companion, pp. 671-674. url=\{http: / / doi .acm.org/ $10.1145 / 2187980.2188177\}$, doi $=10.1145 / 2187980.2188177$, acmid $=2188177$, publisher $=$ ACM, address $=$ New York, NY, USA, keywords $=$ natural disaster, response, social media,.

[24] NugEnt, P. Opportunity structure. https://psychologydictionary.org/ opportunity-structure. 
[25] OnOFRe, J. S. "las tecnologas del sismo". el economista, Sep $2017 . \quad$ https://www.eleconomista.com.mx/tecnologia/ Las-tecnologias-del-sismo-20171001-0101.html.

[26] PALEN, L. Online social media in crisis events. 76-78.

[27] Palen, L., AND LiU, S. B. Citizen communications in crisis: anticipating a future of ict-supported public participation. In Proceedings of the SIGCHI conference on Human factors in computing systems (2007), ACM, pp. 727-736.

[28] Rojas, A. G. "la solidaridad tras el terremoto en mxico: "las lgrimas se me salan sin parar al ver tanta ayuda y or a la gente cantar"'. BBC Mundo, Sep 2013. http : / / www . bbc.com/mundo/noticias-america-latina-41338737.

[29] Rouse, M. What is social media?,2013.

[30] SAGAR, V.C. As the water recedes: Sri lanka rebuilds.

[31] St Denis, L., AND HugheS, A. L. palen (2012).trial by fire: The deployment of trusted digital volunteers in the 2011 shadow lake fire.. In Proceedings of the 9th International Conference on Information Systems for Crisis Response and Management.

[32] Starbird, K., And Palen, L. Pass it on?: Retweeting in mass emergency. International Community on Information Systems for Crisis Response and Management, 2010.

[33] Starbird, K., And Palen, L. (how) will the revolution be retweeted?: information diffusion and the 2011 egyptian uprising. In Proceedings of the acm 2012 conference on computer supported cooperative work (2012), ACM, pp. 7-16.

[34] Tseng, S.-F., Chen, W.-C., And ChI, C.-L. Online social media in a disaster event: Network and public participation. In Digital Information and Communication Technology and Its Applications (Berlin, Heidelberg, 2011), H. Cherifi, J. M. Zain, and E. ElQawasmeh, Eds., Springer Berlin Heidelberg, pp.256-264.

[35] UNAM. "magnitud de un sismo". Servicio Ssismologico Nacional, Jan 2017. http://www.ssn.unam.mx/jsp/reportesEspeciales/ Magnitud-de-un-sismo.pdf.

[36] UNAM. "sismo del da 19 de septiembre de 2017, puebla-morelos (m7.1)". Servicio Ssismologico Nacional, Sep 2017. http://www.ssn.unam.mx/ sismicidad/reportes-especiales/2017/SSNMX_rep_esp_20170919_ Puebla-Morelos_M71.pdf.

[37] White, J. I., Palen, L., And Anderson, K. M. Digital mobilization in disaster response: the work \& self-organization of on-line pet advocates in response to hurricane sandy. In Proceedings of the 17th ACM conference on Computer supported cooperative work \& social computing (2014), ACM, pp. 866-876.

[38] Wulf, V., Misaki, K., Atam, M., Randall, D., and Rohde, M. 'on the ground'in sidi bouzid: investigating social media use during the tunisian revolution. In Proceedings of the 2013 conference on Computer supported cooperative work (2013), ACM, pp. 14091418. 
[39] YAng, L., Sun, T., Zhang, M., And MeI, Q. We know what@ you\# tag: does the dual role affect hashtag adoption? In Proceedings of the 21 st international conference on World Wide Web (2012), ACM, pp. 261-270.

[40] Yang, S., Chung, H., Lin, X., Lee, S., Chen, L., Wood, A., Kavanaugh, A. L., Sheetz, S. D., Shoemaker, D. J., And Fox, E. A. Phasevis1: What, when, where, and who in visualizing the four phases of emergency management through the lens of social media. In ISCRAM(2013).

[41] Yin, J., LAmpert, A., CAmeron, M., Robinson, B., And Power, R. Using social media to enhance emergency situation awareness. IEEE Intelligent Systems 27, 6 (Nov 2012), 52-59. 